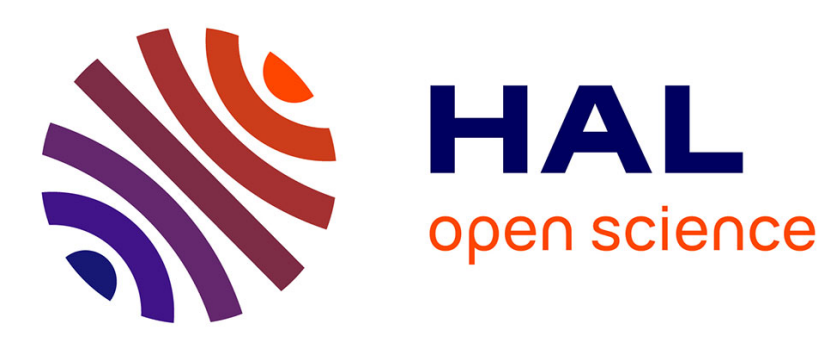

\title{
Resilience in Fukushima: Contribution to a Political Economy of Consent
}

\author{
Thierry Ribault
}

\section{To cite this version:}

Thierry Ribault. Resilience in Fukushima: Contribution to a Political Economy of Consent. Alternatives, 2019, 44, pp.94 - 118. 10.1177/0304375419853350 . hal-03008061

\section{HAL Id: hal-03008061 https://hal.univ-lille.fr/hal-03008061}

Submitted on 12 Dec 2020

HAL is a multi-disciplinary open access archive for the deposit and dissemination of scientific research documents, whether they are published or not. The documents may come from teaching and research institutions in France or abroad, or from public or private research centers.
L'archive ouverte pluridisciplinaire HAL, est destinée au dépôt et à la diffusion de documents scientifiques de niveau recherche, publiés ou non, émanant des établissements d'enseignement et de recherche français ou étrangers, des laboratoires publics ou privés. 


\title{
Resilience in Fukushima -
}

\section{Contribution to a political economy of consent}

\author{
(version auteur)
}

Thierry Ribault

Centre Lillois d'Etudes et de Recherches Sociologiques et Economiques-UMR CNRS 8019, Université de Lille, Bâtiment SH2, Villeneuve d'Ascq Cedex, Lille, France.Email: thierry.ribault@univ-lille1.fr

Article paru dans :

Alternatives: Global, Local, Political

2019, Vol. 44(2-4) 94-118

DOI: $10.1177 / 0304375419853350$

journals.sagepub.com/home/alt

\begin{abstract}
This article is a contribution to the political economy of consent based on the analysis of speeches, declarations, initiatives, and policies implemented in the name of resilience in the context of the Fukushima nuclear disaster. It argues that, in practice as much as in theory, resilience fuels peoples' submission to an existing reality - in the case of Fukushima, the submission to radioactive contamination-in an attempt to deny this reality as well as its consequences. The political economy of consent to the nuclear, of which resilience is one of the technologies, can be grasped at four interrelated analytical levels adapted to understanding how resilience is encoded in key texts and programs in the wake of the Fukushima Daiichi accident. The first level is technological: consent through and to the nuclear technology. The second level is sociometabolic: consent to nuisance. The third level is political: consent to participation. The fourth level is epistemological: consent to ignorance. A fifth cognitivo-experimental transversal level can also be identified: consent to experimentation, learning and training. We first analyze two key symptoms of the despotism of resilience: its incantatory feature and the way it supports mutilated life within a contaminated area and turns disaster into a cure. Then, we show how, in the reenchanted world of resilience, loss opens doors, that is, it paves the way to new "forms of life": first through ignorance-based disempowerment; second through submission to protection. Finally, we examine the ideological mechanisms of resilience and how it fosters a government through the fear of fear. We approach resilience as a technology of consent mobilizing emotionalism and conditioning on one side, contingency and equivalence on the other.
\end{abstract}

\section{Keywords :}

nuclear ; Fukushima ; resilience ; consent ; empowerment ; disaster ; risk communication ; production of ignorance 


\section{Introduction}

The Fukushima Daiichi nuclear power plant was hit by a massive quake and a tsunami on March 11, 2011. The accident, rated at the top Level 7-"major release of radioactive material with widespread health and environmental effects requiring implementation of planned and extended countermeasures"- on the International Nuclear and Radiological Event Scale, is still out of control. The melted-down cores of Units 1-3 remain inaccessible. For Cesium-137 alone, the release was equivalent to between 168 (accessed May 3, 2019, http://www.meti.go.jp/press/ 2011/03/20120330001/20120330001-2.pdf) and 617 Hiroshima bombs, compared to 800-1,000 times in Chernobyl (Koide, 2014). The fuel pools containing 1,573 spent and unspent fuel rods inaccessible to humans are among the highest risks in the event of another major earthquake.

Continued injection of water and overflowing radioactive polluted water are two main issues. Tokyo Electric Power Company (TEPCO), the operator, has the capacity to store up to 1.37 million tons of water through 2020 , but more than $80 \%$ of water stored in large, densely packed tanks (currently 1 million tons) contains radioactive iodine, cesium, and strontium exceeding limits for release into the environment (The Japan Times, September 29, 2018).

The endless work for containing radioactivity entails worker's irradiation. Over 50,000 liquidators have been working at the plant, a large proportion of them without any dosimeter during the first months; 26,000 workers have been mobilized on the decontamination sites in the Fukushima Prefecture, with a violation rate of the labor regulation of $68 \%$, one third being relevant to exposure-related safety and health (accessed May 3, 2019, http://www.mhlw.go.jp/english/topics/ 2011eq/workers/dr/dr/pr_130724.html).

Based on World Health Organization (WHO) and TEPCO data and models, the International Physicians for the Prevention of Nuclear War (2016) calculated that of the 23,172 workers deployed on the power plant site during the first year of the disaster, between 28 and 115 are expected to develop radiation-induced cancer as a result and half will die of it. For the general public, expected additional cancer cases overall in Japan are between 22,000 and 66,000, half of these will be fatal.

On December 27, 2018, the total number of thyroid cancer cases was 218 among the 370,000 people of the Fukushima Prefecture who were 18 or younger at the time of the accident (accessed May 3, 2019, http://www.pref.fukushima.lg.jp/uploaded/attachment/303578.pdf), amounting to 50 times the national average rate (Tsuda, Tokinobu, Yamamoto, \& Suzuki, 2015). Evacuation has been mandatory in an area of about 1,000 square kilometers (390 square miles), around the plant, but since $40,000 \mathrm{~Bq}$ per square meter is the limit over which an area is normally designated as a "control area," some experts (Hirano \& Kasai, 2016) consider that the size of the evacuation area should have been about 140,000 square kilometers (50,000 square miles), which means a large part of the Tohoku and Kanto regions should have been evacuated.

While centered on Fukushima, nearby parts of Ibaraki, Gunma, Chiba, Miyagi, Tochigi, Chiba prefectures, and Tokyo have also been contaminated. It is about 10 million persons concerned, daily exposed to radiation. Officially, 175,000 refugees, of which 70,000 who left the Fukushima Prefecture, were displaced (80,000 mandatorily). In the name of an intensive "return" policy, the provision of free temporary prefabricated housing as well as private rental accommodation publicly paid for and compensation for property and monthly consolation payments from TEPCO to mandatory evacuees from the designated evacuation areas preliminarily labeled "difficult to return" have been progressively ceasing while the evacuation orders are lifted. Such is the context in which the authorities have been incrementing a "resilience policy" for eight 8 years since the beginning of the disaster. 
Critical approaches of resilience can be found in the literature, particularly dealing with its embeddedness in neoliberalism (Chandler \& Reid, 2016; Evans \& Reid, 2014; Hall \& Lamont, 2013) and/or with the fact that resilience favors the constant adaptation of the subject to current situations over the resistance to the conditions of its suffering (Illouz, 2007; Illouz \& Cabanas, 2017; Welsh, 2014). However, critical studies of the implementation of the concept of resilience in nuclear disaster management are nearly inexistent, with the notable exception of two short and unsystematic contributions by Asanuma-Brice (2015) and Tonaki (2016). In their analysis of Fukushima nuclear disaster, Sato and Taguchi (2016) utilize Derrida's concept of "imminence," Kimura $(2016,2018)$ focuses on deployment of affective tropes as a crucial technique of neoliberal governmentality, and Nadesan $(2013,2019)$ relies on the concept of "nuclear governmentality."

While these works offer important theoretical perspective in explaining the implications of Fukushima nuclear disaster, they do not directly tackle the notion and the policies of resilience. In this context, we fill this gap in the literature by proposing a sociopolitical analysis of speeches, declarations, initiatives, and policies implemented in the name of resilience in the context of the Fukushima Daiichi nuclear disaster. We argue that, in practice as much as in theory, resilience fuels peoples' consent to an existing reality-in the case of Fukushima, the consent to radioactive contamination - in an attempt to deny this reality as well as its consequences.

The political economy of consent to the nuclear, of which, we will show, resilience is one of the technologies, can be grasped at four interrelated analytical levels, adapted to understanding how resilience is encoded in key texts and programs in the wake of the Fukushima Daiichi accident. The first level is technological: It refers to consent through and to the nuclear technology. The second level is sociometabolic: Consent to nuisance makes the "living with" motto becoming inescapable. The third level is political: Consent to participation establishes through comanagement of the aftermath the deresponsibilization of those responsible. The fourth level is epistemological: By consenting to ignorance, the public learns how to ignore what it already knows concerning the health effects of radiation exposure. A fifth cognitivo-experimental transversal level can also be identified: Consent to training, learning, and experimentation.

The primary materials mobilized in this contribution are nondirective as well as semistructured individual and focus group meeting interviews during our fieldwork in Japan between 2011 and 2017, with nuclear disaster evacuees, rehabilitation policy makers, radiobiology, epidemiology, and nuclear reactor experts. This article also draws on conference proceedings, publications, and literature from various Japanese and international sources including the "Ethos in Fukushima" "citizen" initiative created by a local nongovernmental organization (NGO), whose name refers explicitly to the ETHOS accommodation program developed at Chernobyl. It led to the implementation of the International Commission for Radiological Protection's (ICRP) "Fukushima Dialogue Initiative on the Rehabilitation of Living Conditions after the Fukushima Accident," in the form of 14 participatory seminars between November 2011 and December 2015, bringing together scientific experts and groups of citizens concerned with "revitalizing" the contaminated areas.

In addition, we draw on the experts' symposia and academic conferences organized between 2011 and 2016 by the Fukushima Medical University (FMU) in charge of the Fukushima Health Management Survey. Materials and interviews from the Fukushima Future Center for Regional Revitalization (FURE) of the University of Fukushima are also utilized. ${ }^{1}$ We will also refer to material from conferences undertaken in Japan by the Citizen-Scientist International Symposium on Radiation Protection 2011-2016, a citizen initiative dedicated to the gathering of the latest scientific findings on health effects of ionizing radiation and sharing them with citizens.

We first analyze three key symptoms of the despotism of resilience: its ubiquity, its incantatory feature, and the way it supports mutilated life within a contaminated area and turns disaster into a 
cure. Then, we show how, in the re-enchanted world of resilience, loss opens doors by paving the way to new "forms of life," first through ignorance-based disempowerment; second through submission to protection. Finally, we examine the ideological mechanisms of resilience and how it fosters a government through the fear of fear. We approach resilience as a technology of consent mobilizing emotionalism and conditioning on one side, contingency and equivalence on the other.

\section{DESPOTISM OF RESILIENCE}

Resilience has been widely used to describe and assess the reactions of individuals, groups, or systems facing disruptive events (Adger, 2000; Folke, 2006). Three distinct forms of resilience are articulated in the literature: biological, psychological, and social. Yet the way resilience is invoked and experienced across those different forms might rather be ambiguous and unclearly defined in the context of exposure to ionizing radiation.

In this context, we show that facing the aporia of biological resilience, it is actually psychological and social resilience which are mobilized and emerge as the governable spaces. As individuals are called upon to act upon themselves hygienically to measure and mitigate radiation exposure after catastrophic levels of contamination, the proposed responses consist in shifting the target for resilience from biology to individual psychology and to society. Resilience is thus operating as a governing technology-more specifically as a technology of consent-that displaces some problems - here the irreversible biological effects induced by radiation exposure-by offering substitute problems such as empowering individual and rebuilding communities. Consequently, it is psychological and social resilience, not biological, which is incanted.

\section{Ubiquity and Ambiguity of Resilience}

The change during the last four decades in the orientation of the research on resilience has been from behavioral and psychosocial correlates of, and contributors to, the phenomenon toward examining biological correlates or contributors (Cichetti, 2010 ; Luthar, 2006). Aiming at better preparing the species for a host of possible environmental challenges, researchers involved in the biological forms of resilience consider situations of exposure of individuals to environmental stressors and the adaptability of their neurochemical stress response system to new adverse exposures, as well as the function of the neural circuitry involved in stress responses (Feder, Nestler, \& Charney, 2009).

Nevertheless, in a situation of exposure to ionizing radiation, examining biological correlates of or contributors to resilience does not mean examining the conditions of a de facto biological resilience, that is, abilities of coping with biological decay. Exposure to ionizing radiation produces genetic and epigenetic effects in the absence of other stressors. It interacts directly or indirectly with the DNA in the exposed cell and can lead to changes in the structure of DNA such as point mutations or rearrangements associated with cancer development. We also know that cells can be rendered unstable both by direct exposure to radiation and by being in the vicinity (bystanders) of an irradiated cell and that the instability may be propagated over many cell generations (Baverstock, 2013).

Consequently, the basic idea of resilience advocates according to whom to be resilient does not only mean to be able to live in spite of adversity and suffering but to be able to live thanks to adversity and suffering (Marquis, 2018) appears to be unworkable in the radiation world.2 
Yet the concept of resilience reemerged with unusual enthusiasm within Japanese scientific circles soon after the beginning of the Fukushima Daiichi nuclear plant accident, on March 11, 2011 (Furuta, 2013). This psychosocietal resilience engineering, where society and individuals are expected to deploy their "ability of restitution" and "flexibility" to overcome-that is "to receive and not avoid" - the "uncertain shocks in order to rebuild a system" (Kitamura, 2011), closely resembles an engineering of toughness and consent to disaster and the harm it causes, where only she or he who knows how to suffer has the ability and the right to survive.

In June 2012, the Japanese Government published its White Paper on Science and Technology, entitled "Toward a Robust and Resilient Society" aiming at "nurturing the dreams and hopes of the people," considering that: "[r]esilient community is a group of people organized and structured to adapt quickly to change, overcoming trauma, while maintaining its cohesion and open relationship with the rest of the world" (MEXT, 2012, p. 2).

In December 2012, Keiji Furaya became the first "Minister in Charge of Building National Resilience." The "Basic Plan for National Resilience" was adopted on June 3, 2014. Using a rather unclear definition of what "national resilience" means, the main objective of this act is to reinforce centralized power, stipulating that "citizens must work in cooperation with the resilience policies" (Mainichi, October 7, 2013). S. Mimura, the head of "disaster mitigation" at the Fukushima Future Center for Regional Revitalization, shed light on the concrete objectives of a policy of resilience by stating that:The damage caused is a balance between the impact of the disaster and the public's ability to accept it. [Therefore] actors must integrate a culture of awareness of disaster. [This means that] we must work on behavior [...] More specifically, for nuclear power, this means developing evacuation routes [...] We have an evacuation plan to encourage people to come back, but what will we do in panic situations? We must thus integrate disaster preparedness in the reconstruction plan. (Interview by C. Asanuma and the author, Fukushima, June 6, 2014) When, during the interview, we pointed out that we were, in fact, in the midst of the disaster and that it might, therefore, be not a question of preparing for the next one but rather of trying to deal with the consequences of this disaster, Mimura responded:I cannot predict what will happen with this disaster. Although we are trying to raise awareness, we cannot predict people's reaction. I cannot provide a concrete plan for evacuation. In other words, they have to save their lives by themselves. That's why one has to know his or her level of radioactivity. If you count on others and on the government, you may go through an unfortunate experience.Its cracks already apparent, the reassuring structure of resilience collapsed entirely with the humble conclusion drawn by Mimura, who had suddenly become more realistic: "[a]dmittedly, it is not possible to be sufficiently resilient to radioactivity to accept its impact. What we can do is reduce the risk but we cannot accept because once affected, recovery is impossible."

\section{An Incantatory Process}

The realism of this admission of the incantatory nature of resilience - attesting the chimeric feature of its biological form in a situation of radioactive contamination-is not, however, the most widespread view. Indeed, today's trivialization of the notion of "resilience" - a notion known to all but whose political function remains poorly defined, albeit brandished by everyone-to address what is now considered as an essentially psychological or even psychiatric problem among the people living in contaminated areas of Tōhoku, speaks volumes about the representation of the "nuclear crisis" in terms of "trauma." This representation urges everyone to fight their "depression" by focusing on individual qualities and on the opportunities provided by their environment in order to return to a "pretraumatic" state by the combined grace of "rebound" and "resistance to shock" and, incidentally, selective amnesia. More precisely what does the incantation mechanism of resilience consist of? 
Proponents of resilience create a pseudotherapeutic tool that makes it possible to conceive the (essentially psychosocial) dysfunction that this tool can treat. In other words, they conceive a perfect disaster that socially suits the terms of its resolution, terms that resilience provides. Resilience thus defines the outcomes and makes of disaster a means through which to achieve these outcomes. This is quite close to narrative communication techniques with therapeutic objectives, still referred to as "storytelling," insofar as the language of resilience, at least as it is used in the nuclear disaster context, belongs to the same type of authoritarian ritualization of speech. Psychosocial resilience, a subbranch of consent engineering, makes it possible to solve the aporia of the biological detrimental effects of radiation by developing a tailor-made disaster consisting in substitute problems and challenges such as empowering individual and rebuilding communities. It does not deny the disaster itself, but it rewrites it or transforms it into an event that may be rewritten, making a story out of it, several stories even, as many as individual experiences, on condition that these experiences are "forward-looking."

Conceived as the art of saving oneself, psychosocial resilience seems perfectly suited to less and less controllable disaster scenarios because it makes it possible to shift responsibility from the society to the individual and to shift causal analysis toward the fields of subjective perception and representation. Meanwhile, dismissing objectivity means dismissing the mechanisms subjects obey.

The literature on resilience emphasizes the need for "adaptive comanagement" and "reflexive governance" that are considered appropriate to respond to change, uncertainty and complexity (Frantzeskaki, Loorbach, \& Meadowcroft, 2012; Voß \& Bornemann, 2011). Resilience is also associated with polycentric and multilayered institutions as well as with principles of participation and collaboration, self-organization and networks, and learning and innovation (Pisano, 2012).

Many works on the post-Fukushima disaster highlight the emergence of an entrustment of protection to the people, reflected in particular in the fields of the measurement of radioactivity in the atmosphere, water, ground, and food, of assistance and medical examination, or in the assistance of the relocation of nuclear refugees (Kera, Rod, \& Peterova, 2013). The notion of "emergent concerned groups" and "civic infrastructure" have been developed (Funabashi \& Kitazawa, 2012; Morita, Blok, \& Kimura, 2013), while a large amount of STS studies literature emphasizes participative and inclusive approaches when choosing and managing technology (Biello, 2011; Hindmarsh, 2013). Such highlight of horizontalization of protection and of autonomous and nonhierarchal protection systems raises the issue of overvalorization which has become systematic, of "ordinary people" in disaster situations, an overvalorization largely nourished by the followers of the concept of resilience paying little attention to the public health reality of a nuclear disaster, and the degradation that "resilient people" undergo because of this reality.

Yet, for instance, the work of the Atomic Bomb Casualty Commission (ABCC)-RERF ${ }^{3}$ on longterm health effects of exposure to whole body radiation from gamma rays and neutrons on atomic bomb survivors and residents of Hiroshima and Nagasaki has shown highly significant increases in incidence of a wide range of cancers. Most of these risks were not established until decades after exposure but still continue. For those exposed as young children, now in their 70s, the excess absolute risks have increased as the population ages. A number of noncancer diseases have also increased in incidence many decades after exposure, that is, circulatory (heart attacks and stroke), respiratory (pneumonia), digestive (cirrhosis), infectious (tuberculosis), and other diseases such as urinary diseases (Ozasa et al., 2012). However, by obscuring the impossibility of biological resilience unveiled by such scientific outcomes and by viewing disasters as manageable events, the discourse and actions taken in the name of some form of humanitarian realism contribute to the approval, or even the acclamation of a society that feeds off disaster. 
Indeed, followers of the laboratory world, that is, a world that has become a permanent and collective experimentation laboratory, never fail to point out the multiple ongoing initiatives aimed at establishing the Fukushima disaster as a source from which to "bounce back" and make other "advances" essential to survival in "sustainable submission" (Semprun \& Riesel, 2008). The creation, in the wake of the 2011 disaster, of the "International Research Institute of Disaster Science" at Tōhoku University, with the cooperation of the Harvard Humanitarian Initiative, is a notable example aiming at "becoming a world center for the study of the disasters and disaster mitigation [...] and pursuing effective disaster management to build sustainable and resilient societies" (accessed May 3, 2019, http://irides.tohoku.ac.jp/eng/outline/index.html). Other actions are underway, and these range from robotic, agronomic (on rice resistant to cesium and other bioremedial alternatives), biological, and medical experiments (especially in radiotherapy and gene therapy) to architectural and urban planning experiments including land deregulation, smart cities, and other smart communities projects.

Resilience is thus a matter of creating technically what Sebald (2004) referred to as a "faceless reality" after analyzing the perception of the disastrous and horrific aftermaths of the bombing of German cities during World War II. This reality prevents one from seeing and describing the material and moral destruction faced by a section of the country's population and makes it possible to stifle the need for critical knowledge under the soft pillow of the tendency to turn a blind eye. In its psychological and social incanted forms, resilience is mainly a means through which to seal the taboo that weighs on physical, material, and psychological destruction. Thus, as Sebald (2004, p. 23) notes: The collective desensitization resulting from such a process strengthens the mechanism of repression which, while recognizing the absolute disrepair from which the new situation sprang, eliminates from its emotional heritage, or puts down to glorious facts, all that this new situation has been able to overcome without showing the least weakness of character. Although taking the appearances of a therapy, resilience is in fact an anti-therapy: It is the opposite of an overcoming through awareness. Instead of bringing about into the conscious the repressed causes of misery, resilience perpetuates in everyone the dependency on the subconscious giving hope for justice and faith in the future, since things really have to get better and better. In their inability to consider what is negative advocates of resilience demonstrate a true negaphobia. This denial of the present as well as conjuration around memories reveals a second way in which the immediate history is eliminated. This consists of orienting the people to look only to the future-a key feature of the resilience paradigm - and to keep all their experiences silent, or at least to operate a selection among their affects, as discussed later.

Much is at stake in this "spatialization of time" (Gabel, 1962): Come to the rescue of a bankrupt nuclear industry, achieve reconstruction and, in Japanese megacities, put money back to work in double-quick time, get everyone back to her or his post, that is, consumer and producer. Indeed, we can talk about spatialization of time when, for instance, the Japanese authorities establish a "returning calendar" for the nuclear refugees, while actually referring to a time which is not historical since it denies the irreversibility of time by denying the irreversibility of radioactive contamination and of its biological effects. While in space, before and after have a relative significance-returning is possible-in time, their significance is absolute-returning is impossible. Through the spatialization of time before and after are relativized. Actually, the substitution of a move in space for a move in time mirrors the substitution of psychosocial resilience for biological resilience.

The disaster's managers, however, do not recommend the outright liquidation of humanity but instead, prepare everyone for morbidity and death, a social utility that has become a soft instrument of repression which introduces an element of surrender and submission. They reconcile people with the idea that dying before they would like to or before their time is now not only highly probable but is part of human (industrial) civilization. They yearn for a consenting society that takes upon 
itself what each one should eventually be able to take on him or herself. The toughened-and "resilient"-individual is the best thing in a toughened-and "resilient"-society. Rooted to the spot Novhomme (or Newman), this robust woman/man expected to rapidly adapt to life in a contaminated territory, thanks to a few technological advances in terms of remediation and some sociopsychological and genetic adaptations, appears to be the agenda.

This is why, after noting that victims of psychopathological disorders resulting from a disaster are often predisposed to mental disorders and past trauma, planning ahead, the psychiatrist Craig Katz (2013, p. 33) of the Icahn School of Medecine in New York, recommends that we "make the people mentally healthier before the disaster, so that they can be better prepared when disaster strikes." Thus, according to him: "[p]hysical exercise, active coping, a positive outlook, a moral compass (spirituality for instance), social support and cognitive flexibility" are considered "factors of resilience" that make it possible to mitigate the traumatic effects of a nuclear disaster.

From genetic predisposition testing to diseases and anxiety of memories, to psychological predisposition testing, under the guise of recapturing self-governance, the objective is to comply with the fate of existence. This fate is the following: The individual is alone with his or her heritage of adaptive capacities, but fortunately, when this heritage is depleted, the science of resilience intends to enrich and strengthen it in order to help him or her to face disasters with serenity. In other words, everything we had that was confiscated by the disaster, resilience promises to resell it to us, upgraded.

However, during an interview, we asked Katz whether in his opinion scientific criteria making it possible to truly implement the resilience he was calling for existed and whether these criteria would enable to account for the effectiveness of this recommendation. The scientist simply and honestly responded "no," hence acknowledging the extent to which the so-called resilience is indeed a pure incantatory process (interview by C. Asanuma and the author, FMU, November 24, 2013). Under the guise of science, resilience has in fact more to do with "beliefs," meaning that it has an unlimited potential for application. Believing in resilience does not mean though that any resilience has yet been achieved.

\section{Supporting Mutilated Life Within a Contaminated Area and the Turning of a Disaster Into a Cure}

A crucial feature of the political economy of consent conveyed by resilience is the consent to threat. Mutilated life refers to the transformation of the existence into an indefinite management process of this threat be it biological or social. From everyday monitoring of the living environment - ambient dose rates in living places, external and internal individual doses, and contamination of food products - to the medical lifelong control, care and cure of the long-term diseases (and its economic consequences) potentially induced by exposure to ionizing radiation, mutilated life is a life which does not live because it is submitted to a complete organization and to the permanent control of an instrumental rationality.

\section{Surviving Through "Dialogues"}

By calling on individuals' "accumulated capacities," including resistance to irradiation, each one is now expected to mobilize her or his reserves of resistance to the irresistible, a superfluous ambition of the followers of resilience. The negative becomes positive even when it is life itself that is stolen. This stolen life begins when all self-confidence is lost, and the individual is no longer able to tackle head-on the representations and actions that seek to transform death into a source of life. 
Contrary to the claims made by some radiation protection experts, life is not based on death, and adversity is not a merit. However, we are in Fukushima, where a process seeking to undermine the credibility of science and to delegitimize it is calling on the people to take part in a "common practical culture of radiological protection" and to each become actors of their own protection, that is, to become responsible for what they are not, and to transform the distress perpetrated by society into individual manageable cases.

This, for instance, is the key objective of the "dialogues" organized by the ICRP in Fukushima, which urges each individual, in the name of the primacy of "everyday life," to become a "stakeholder" of her or his own irradiation. Naturally, all this with talk of "accountability" and "empowerment," glorifying the cultural roots and praising the merits of a "dialogue gradually laying the groundwork for local initiatives that, in turn, help individuals to regain control over their daily lives and once again act according to their desires and wishes," in order "to change the perspective from 'authorities make plans for the population' to 'authorities make plans with the population"” (IRSN, 2016), while established scientific truths regarding detrimental health effects of radiation exposure, now judged relative, uncertain, and questionable are thrust aside.

Lochard (2011), a leading postaccidental nuclear consultant, vice-chair of the main commission of the ICRP, key promoter of the self-protection doctrine after the Chernobyl nuclear disaster, who facilitates these "dialogues" with a selection of Fukushima "citizens," writes that "[t]he message I heard [in Belarus] was something like: life is stronger than death [...] those who have passed though this experience have something more inside of them. They are stronger." Such is the nuclear populism sanctifying sufferings considered as a source of moral superiority, and the underlying denial of the real and multiple effects of radiation on life forms. ${ }^{4}$

"Life is hard, but this hardship makes it beautiful and healthy" is the leitmotiv of these cold blooded amateurs who justify their appeal to people's emotions by claiming that this is what the world requires. By equating honor to suffering with virility and accepting the suffering despite all costs, they attempt to make accept that, in an upsurge of profitable destructiveness and equivocal generosity, on condition that it is managed based on the virtues required of citizens, disaster makes the man, and not the other way around.

The "living with" contamination program implemented in Fukushima, with the support of international bodies, aspires to encourage the population to survive endless adversity. Meanwhile, here lies the limitation of certain so-called citizen actions in Fukushima which tend to transform the said "citizens" into comanagers and stakeholders of nuclear damage.

The injunction issued to the people of Fukushima, to be contaminated and satisfied - the real victim being the tarnished image of the nuclear industry in the wake of the disaster - is echoed by Shinichi Niwa, who heads the Psychiatric section of the Health Management Survey at FMU. He points out that "[p]eople can feel secure if they do decontamination work themselves, rather than if they let others do it for them" (Mainichi, March 26, 2012), which is a way to produce consent by transforming an exogenous pressure into an endogenous motivation. Administering the disaster in the same way one would administer drugs, the decontamino-therapist proceeds by noting that "[i]t is very important to ease anxieties through radiation exposure."

Thus, this "living with" contamination, and therefore with the decontamination whose effectiveness is yet to be proven and that should rather be called toxic relocation, has become the fatal outcome of the disaster and the only "reasonable" discourse in Fukushima. The comanagement of the damage is irreversibly desired, lauded by all in the name of the need to overcome the situation, to heal through disaster, and set in some form of "protection" based on this art of accommodating leftovers known as resilience. 


\section{Becoming a World Para Athletics Champion}

Some months after the disaster started, Hériard Dubreuil (2011, p. 73), an expert known for his commitment to Chernobyl, alongside Lochard, in ETHOS (1996-2001), SAGE (2002-2005), and CORE (2003-2008) programsjects funded by large European and international grants, and whose main objective is to make recommendations on how people may accommodate radioactivity, freely shared his questionable and overwhelming support of mutilated life in contaminated areas and on what it is based, that is, disaster as a cure, stating:Rather than talking about returning back to normal life, I prefer to talk about the rehabilitation of dignified living conditions or the quality of life. In any case, it's something new. It's like someone becoming paraplegic, then winning in the World Para Athletics Championships. That would be something else, it wouldn't be as before.In this glorification of life at all costs, even at the cost of morbidity, all pro-life ideologies are mobilized in an attempt to support the making of nuclear power and its damages both natural and inevitable. One must recognize the cynical realism of the image of the winning paraplegic champion to represent a radioactive contamination that becomes a resource allowing those most directly affected to continue the competition - that is, survival - in the best possible conditions - that is, infirmity and disease with the hope of becoming heavily doped "world champions" who will eventually completely decay in all "dignity." Nestoroska (2017), Emergency Officer at the International Atomic Energy Agency, seems to draw from the same type of esoteric terminology, arguing that: "Iimproving resiliency during recovery can result in a resilience new normal" while "longer recovery times add cost and may result in a diminished new normal."

Such call for the victims to transform their disabilities into virtues and to surpass themselves means in this context that unconsciousness becomes a precondition for success. At stake, therefore, is the ability to create a new reality that will emerge in part from the process of self-censorship that seeks to conceal a world which progressively becomes meaningless. In this world, victims eventually accept their share of responsibility, which prevents them from "saying it all" and "showing it all" and the internalization of suffering eventually prevails as the only possible option. Such despotism of resilience can function only if it is based on the principle of the comanagement of nuclear damage because comanaging helps bridge the gap between what is actually terrible and compliance with that which is terrible. It also drives one to consent to contamination and teaches individuals to live in poor living conditions.

Moreover, it leads to the infiltration of this perception in mass culture. Falling within the paradigm of order, rather than that of transformation, comanaging provides support for the everyday agony of the body and, equally serious, of the mind and its potential opposite view. Identifying with what is feared plays a major role as comanagement tends toward self-management, which to the nuclear disaster is similar to what self-criticism meant for Stalinism: Aat technique to internalize guilt and, in so doing, domination because comanagement refers to the congestion of freedom and of the refusal to be deprived of this freedom.

Meanwhile, the less the people have the freedom of choice and moral responsibility, the greater is their practical liability: Each individual is summoned to share in the management of the damage caused, to measure, to act as a citizen, and to contribute to the repairs, thus becoming responsible for a decision she or he did not make or one from which her or his participation was denied. Under such "privatization of risk" (Nadesan, 2013), which reflects the collectivization of the self, this morbid rationalization of daily life is so immense that one might say it borders on madness. Never has the nationalization of the people been so demanding. 


\section{LOSS OPENS DOORS}

In the reenchanted world of resilience, loss opens doors, that is, it paves the way to new "forms of life." This is the key point of the Ethos in Fukushima "citizen" initiative, mentioned in our Introduction section, whose slogan is: "This is about living in Fukushima after the nuclear disaster. More, it is about our ability to pass on a better future, as living here is a wonderful thing" (accessed May 3, 2019, http://ethos-fukushima.blogspot.com/).

Two main features of these new forms of life induced by resilience-based policies can be distinguished. The first one is what we call an ignorance-based disempowerment. We will show how psychologization is at the center of the consent to ignorance and relativization of existing knowledge, leading to a dispossession of power. The second feature is the submission to protection through self-management of disaster and its aftermath, as a modus operandi of resilience. Consent itself appears as a protection consisting for everyone in vanishing into the anonymity of the administered community.

\section{Ignorance-Based Disempowerment}

According to the officials of the "Ethos in Fukushima" and the subsequent ICRP "Dialogues" initiatives, many government actions geared toward the protection of the people are technocratic and hardly correspond to the specific needs individuals require based on the reality of their situations. This is true, for instance, with regard to wearing masks and prohibiting children in areas considered contaminated from going outdoors. Following this observation, the concept of selfprotection consists of "[e]mpowering people to know where, when, and how they are exposed, as well as how they may protect themselves from radioactivity" (Lochard, 2011).

Paradoxically, while this approach suggests that public policies are too far removed from the real needs of the people - for instance, arguing that communities have been broken by the authorities who drew "lines which have such strong power over peoples' lives" (Ando, 2016) - it relies on these structures and on the forms of expertise from these very authorities themselves. It reveals the questioning of national or local bureaucracies that led to some form of recovery which, although it undoubtedly immediately appeared less bureaucratic - the NGOs and the organization of the socalled dialogues - was simply highly structured international management driven by relatively remote bodies (International Commission for Radiological Protection, International Atomic Energy Agency, United Nations Scientific Committee on the Effects of Atomic Radiation, and World Health Organization), far removed from both the local context and from the direct concerns of the inhabitants.

In such form of "conflictual collaboration," as tackled by Polleri (2019), where the citizen scientists counterexpertise, while resisting to Japanese state's practices of monitoring radioactivity, evolves into "collaboration with the state politics of governance, legitimizing hegemonic visions of radiation danger and normative vision of recovery" (p. 216), involved inhabitants perceive themselves responsible for becoming "experts of their own daily lives." However, the ultrademocratic nature of such a posture of the victim-expert-designed to transform the management of nuclear risks into a spontaneous, subjective, local, and pragmatic processcontributes to making comanagers ignore or relativize existing scientific knowledge, including the knowledge establishing a linear relationship between exposure to so-called low-dose ionizing radiation and the health risks involved as well.

Science though is not necessarily on the side of radiation hazards. Research is deeply polarized between defenders of the "linear no threshold" model or LNT dose response, according to which the 
risk of cancer is directly related to the dose, and advocates of hormesis typically arguing that although radiation attacks DNA and causes mutations, DNA repair mechanisms quickly correct these and that we live in a beneficent soup of low-dose radiation, which is essential for life and may even prevent cancer deaths. However, if the hormetic model might actually be suitable for the therapy of sick people, it is considered irrelevant on the healthy population (accessed May 3, 2019, https://www.ianfairlie.org). Above all, available large epidemiological studies show risks declining linearly with dose at very low doses, thus supporting the LNT assumption (Leuraud et al., 2015).

Resilience as it is mobilized in the nuclear disaster management domain appears to be a metastasis of the hormesis belief. The not yet proven syndrome identified by Proctor and Schiebinger (2008) in the health research on tobacco is also very active in the nuclear field: In the name of relativistic pragmatism, individuals are thrust into situations where doubt and ignorance are produced and where confusion about whether to trust scientific truths is bred. For instance, during an interview, Lochard, one of the lead facilitators of the ICRP's "dialogues," said that:Self-protection against radioactivity is like daily hygiene at home with the kids. [...] In the context of everyday life, you know that if you get cut, it's good to disinfect. Well, the same is true with radioactivity [...] From the moment you can adapt this message to everyday life, and help people identify where radioactivity is found, how it reaches them and what they can do to protect themselves, people can turn self-protection into an activity undertaken collectively to try reduce this whole mess in the most rational way possible. (Interview by C. Asanuma and the author, Fukushima, November 22, 2013)In this rather startling scientific approximation, this former economist at the French Atomic Energy Commissariat thus gives the following motive: It is only by behaving in a rational manner, that is, by opening one's internal and external life to full scrutiny, that we may have a slim chance of meeting the irrational requirements of existence in a contaminated area. This, therefore, means that one must adapt. In this context, being rational does not mean that those exposed to irradiation should question the irrational conditions in which they find themselves but rather that they should make the most out of their situation. Put differently, in the name of accountability and the independent ownership of their own destiny, individuals should repeatedly criticize themselves and not the given conditions of the contamination event. Other than benefiting from the irrational, while claiming to be pragmatic, realistic, effective, and adapted to people's specific needs, such approach also undermines the credibility of science and plays down the certainty of scientific results. The same call for relativization of science is made by the experts of the European Commission funded SHAMISEN project (2017, p. 15): "Radiation protection is not only a matter of science, but also a question of values and judgment."

While implicitly containing the promise of a temporary triumph over death, psychologization is at the center of this calling for consent to ignorance: That is, transforming social and scientific reality into a phenomenon requiring an individual assessment based on a subjective perception that depends on the nervous and mental state of each individual. Conforming to the shift in the radiological protection field starting in the 1970 s, from a threshold paradigm to a risk management paradigm (Boudia, 2013), radiation protection standards and dose rates have become pointless for ETHOS's radiologists who consider that standards restrict practices and should be replaced by local "reference values" bearing no regulatory or legal status and which are mere recommendations intended to facilitate individuals' actions. The notion of radiation doses thus becomes obsolete and is replaced by the "annual intake budget." We are in a world of information indicators where "[v]igilance, food rationing, redefinition of geographies and products, but also self-restraint became the new reflexes, virtues and customs that are supposed to permit the empowerment of local populations." (Topçu, 2013, p. 146).

In reality, this shift from radiological protection based on a culture of technical norms to a risk management based on culture and behavior as a norm, this alleged operation of empowerment that ETHOS and its resilience advocates claim to help develop is nothing other than an ignorance-based 
disempowerment, that is, a dispossession of power through ignorance production, which helps channel the horror of radioactive contamination by casting it into pseudorational shapes and thus institutionalizing anxiety itself. According to Lochard (2013):The practical culture of radiological protection can be defined as being the knowledge and competences allowing each citizen to choose and behave wisely in a contaminated environment [...] When people have a direct access to measuring, standards are not any more blocking factors limiting their involvement in the remediation process, and become indicators guiding them in their actions and their everyday behaviors, which means indicators of quality [...]. People move from resignation to creativity.Once again, each term becomes meaningless when spoken by consent mediators who have no qualms about speaking of "creativity" in the fight against radioactivity. What they actually seek through such injunction to translate endured difficulties into a psychic opportunity to reinvent oneself is to use the apparent measurement of danger to deny the danger of measurement. Indeed, measurements can be an obvious trap, that is, the trap of relativism and the absence of the definition of truthmade acceptable by the fact that measurements have become or are perceived as vital-truth that relates to the reality of radiation-induced biological damage.

\section{Submission to Protection}

Displaying no fear of oxymoron in associating healthy life considerations with radiation exposure, Fujino (2013), of the Department of Human Sciences at the Fukushima Medical University (FMU), states that "[t]here is a need for constructive dialogue which will allow us to live in the healthiest way possible in contaminated zones."

An institutional insight of the scientific research in Fukushima might be helpful to contextualize such statement. Indeed, FMU was commissioned by Fukushima Prefecture to conduct the Health Management Survey, launched soon after the disaster to investigate long-term low-dose radiation exposure caused by the accident, using the 714 million dollars "Fukushima Resident Health Fund" from the Ministry of Economy, Trade and Industry in charge of promoting construction of nuclear power plant facilities in Japan (accessed May 3, 2019, https://www.env.go.jp/guide/budget/spv_eff/ review_h24/sheets_h23f/sheets/380.pdf\#3). The aforementioned Radiation Effects Research Foundation (RERF) - former ABCC - and FMU agreed quickly after March 11 to strengthen their collaborative relationship in the field of radiation effects research.

Many victims of the atomic bombings have been blaming the ABCC for treating them like "guinea pigs" and violating their human rights: The ABCC forcibly took them to research facilities where they were stripped naked for tests and to have their photos taken, and bereaved families were asked to donate the bodies of family members who died from radiation exposure (Mainichi, June 17, 2017). The organization has long been criticized for gathering data from hibakusha but not treating them. As stated by Lindee (2016, p. 186), the critic extends to RERF, which is "[b]oth trusted and not trusted, both believed and disbelieved. [...] Trusted as a guide to international radiation protection standards, the RERF scientific program has also been criticized for its inattention to lowdose risks." 5

The involvement of RERF in the Fukushima surveys in collaboration with the FMU can thus be regarded as an element of historical continuity of the ambivalent Japanese public health research on radiation effects. Indeed, Ohtsura Niwa, who has been appointed Special Professor and Chief Scientific Officer for the Health Management Survey at FMU in 2011, was elected RERF's Chairman and Representative Director in June 2015. While recently directly apologizing to 
hibakusha for being badly treated, Niwa strangely reasserted though that "such steps were necessary for the sake of science" (Mainichi, June 17, 2017).

Also, a current member of International Commission for Radiological Protection (ICRP) Main Commission, Niwa has been, from the beginning of the Fukushima accident, among the fervent defenders of the "radiophobia" speculative theory 6 and an influential advocate of the "dialogues" initiatives brought by ICRP (Niwa, Lochard, \& Clement, 2016).

Therefore, the final purposes of the FMU-RERF cooperation are questioned and doubts are cast on the reliability of its population health assessment, considering that the identification and disclosure of any low dose effects could be strongly compromised by premises and prejudices placing greater emphasis on unscientific theories such as "radiophobia" as well as incanted resilience.

As claimed by Hériard Dubreuil, Lavelle, Gadbois, Mays, and Schneider (2010), the real substance of the previously quoted neo-democratic trinkets by the FMU expert Fujino is a question of "transforming the cognitive and normative frameworks" of individuals rather than the reality from which they spring. This planned self-experimentation amounts to death and morbidity conditioning. Entrusting the administration of a disaster to those most directly affected by it is no more than finding guilty she or he who suffers. Self-management, as a modus operandi of resilience, in a situation where public authorities and experts are still in control, ensures the efficient flow of injunctions and orders to those they are intended, while feeding their illusion of participation on which the repression of their submission is grounded.

Perfect adaptation and demonstration of individualism - which transforms itself into the consolation to submission - are actually both required. The population is indeed confronted with a paradox: In order to adapt to the dominant living conditions, one needs to pursue relentlessly one's own selfinterest, and by doing so, adapting through nonadaptation. Like the horoscope, resilience fiddles a universal form to express its hardly compatible requirements: One has to be individual and cooperative at the same time.

The problem, however, is not so much the contradictory nature of the injunction rather than its implemented repressive consistency. The truth is the doctrine of resilience does not expect at all that someone fully subscribes to the social (and sanitary) norms. It only demands to submit oneself, to the extent necessary, to the external requirements, while also encouraging to slide back without scruples into a certain unbridled roughness, as far as there is no concern for punishment. Blind obedience and the lack of introjection of norms actually converge to walk at the same pace. Like the horoscope, resilience is a "second-hand superstition" which instils a "non realistic realism" (Adorno, 2011, p. 276). But to whom and to what must one really consent to submit?

In their quest to recover lost growth through "reconstruction Olympics," government authorities and their experts have made ample use of the "return to living in contaminated zones" oxymoron and have stopped at nothing to establish an incestuous, indestructible and indispensable link between protection and submission. Thus, according to J. C. Lentijo, from the International Atomic Energy Agency: "[o]ne can go back to living in a contaminated zone provided that the combined level of external exposure and internal contamination does not exceed 20 millisieverts per year" (Kyodo, October 21,2013), that is, 20 times higher than the current internationally recommended level.

The objective, then, is to protect the psychologically destroyed people by prescribing a return to their "native soil" (Minpo News, October 13, 2013). Asked about the government's responsibility for providing assistance to the so-called voluntary evacuees, Masahiro Imamura, the minister in charge of rebuilding from the 2011 Fukushima nuclear disaster, clearly stated that:They are responsible for their own lives. They can file a lawsuit or do other things if they disagree with the central government's position (...) It is easy for people to leave their homes, but I hope the evacuees 
will show their commitment to returning home and hang in there. (Asahi, April 6, 2017)Withdrawing support to the nuclear refugees not only represents an incentive to stay for the vast majority of those who did not move but is also a way to implement a natural selection where the most suitable people are those who did not run away and consented to face radiation while the deviant fugitives are dissuaded through fiscal and administrative measures. We are not far from the recommendations made by the prefascist German anthropologist Otto Ammon (1896) encouraging natural selection of the most suitable people by exempting them from taxes.

However, since each of the 80,000 inhabitants of mandatory evacuated municipalities living close to the plant is eligible for a monthly 750 dollars allowance for "psychological harm," this embracing of Heidegerrian philosophy by the authorities - where the possibility of death and suffering has to be endured, and never is the subject considered more authentic than in this endurance-has to be placed within its budgetary context. Indeed, the return policy is also motivated by the fact that the government has so far spent approximately 400 million dollars per year in housing assistance for the so-called nonvolunteer refugees. It also supports TEPCO's compensation plan. The bill for compensation has been estimated at 60 billion dollars, and the estimated costs for decontamination work at 310 billion dollars. The cumulative public financial burden of the Fukushima nuclear accident to date stands at 626 billion dollars (Japan Times, April 1, 2017).

It must also be recalled that it is in the name of this faltering protection that the threshold of 20 millisieverts per year "authorizing" the return of the evacuated population was prescribed by the government from December 2011. A not named Minister of State who participated in the preparatory meetings at the time confided that a threshold dose of 5 millisieverts per year - which prevailed in Chernobyl - would have involved the evacuation of too many people in the two largest cities of Fukushima and Koriyama, each of which had more than 300,000 inhabitants. This would have made "the Prefecture normal operations impossible" and also raised "concerns about additional costs of compensation for evacuees that could significantly rise if they were unable to return home in the contaminated areas for a prolonged period" (Asahi, May 25, 2013). Establishing that fear is beyond our means, this at least has the merit of clarity concerning the real motives of the announced policy of resilience.

\section{GOVERNING THROUGH THE FEAR OF FEAR}

Let us return to the ideological mechanism of resilience, that is, its socially necessary appearance as is shaped by its devotees. We will show how resilience can be defined as a technology of consent contributing essentially to transform horror in hope of a reward that never comes that governs through coding the risk as fear itself. And as such it relies on the technologies of radiation monitoring that contribute to quantify risk, albeit with uncertainties and deep conflicts regarding interpretations of health effects. Consent appears here as a process of learning to fear fear itself in order not to fear one's own deterioration and challenging it.

\section{A Technology of Consent}

Adaptation, which is a form of expression of resignation, itself fueled by hope, is a formidable weapon that allows us to eliminate fear. Put differently, it makes it possible to get rid of the consciousness of our powerlessness and thus of the little desire for freedom left in each one of us. As we saw earlier, comanagement of disaster and congestion of freedom are intertwined. Elevated to the rank of "capital risk" not worth being taken, freedom thus becomes a threat requiring a form of management resilience claims to be devoted to. 
Resilience is not only a concept in line with technology, but it itself appears as a technology-as part of the technologies of consent-which rationalizes the lack of freedom by showing that it is technically impossible to be autonomous and to determine one's own life without incorporating certain given conditions. This explains why the lack of freedom does not appear as an irrational or a political fact. Rather, it shows that being subjected to a technical device makes life more comfortable and easier, even if that life is mutilated. That's why, contrary to Herman and Chomsky (1988), we don't center our approach of the "manufacturing of consent" on the mass media but on technology. The following words from the organizers of the "dialogues" can thus be found presented completely unabashedly:Day after day, recording measurement results became an integral part of life for motivated people, just like reading the "best before" date on food and drink packaging. From infants to seniors, from kitchens to bedrooms, from rice to fish, everything has to be measured: mountains, fields, gardens, roads, parking lots, houses, school yards, kindergartens, tap water, meals...Gradually, the Fukushima residents got acquainted with different measurement techniques and equipment. (IRSN, 2016)Indeed, in this dystopic reality presented as desirable, resilience feeds on the desire to be protected by one's own assimilation and one's own close mimicry of the machines: It is a question of being better integrated into their overall functioning. However, as Gonon (2017) highlights:Irrespective of whether they have been displaced or are returning, victims of disasters lead suspended lives in the here and now. Daily life becomes a life of incessant struggle, entirely occupied by the maintenance of biological life, i.e. generally speaking, by the construction of healthy bodies and concern for family safety. And this "biological citizen" behavior seems incongruous; it does not belong to what is perceived as compatible with normal life because it is political in nature.Indeed, the more the toughened subject adapts to the toughened reality, the more she or he becomes an object for her or himself, and even the less she or he achieves to simply live. In such context of dread of the possible, rather than the Geiger counter itself, it is the consent to the chronic slow disaster and to the "morbid geometrization" of everyday life (Gabel, 1970, p. 99) that are favored by resilience. Given the continuous monitoring of the radioactive environment to which people living in contaminated zones are subjected to, this resilience perfectly illustrates the legitimate domination by a technological rationality according to which " $[\mathrm{w}] \mathrm{hat}$ is reasonable is the optimal functioning of the social mechanism, namely, functioning that delays disaster, without questioning whether or not this mechanism in its entirety is optimal de-reasoning". (Adorno, 2003, p. 41).

\section{Emotionalim and Conditioning}

Why in the context of resilience is freedom, particularly freedom to fear, a threat to be managed? For the "dialogues" experts, there is no ambiguity: The objective is to "release" everyone's anxiety and, "in the process, to shift their own status from helpless on-lookers to forward-looking stakeholders" (IRSN, 2016).

One of the pillars of the political economy of consent in the nuclear is a regime of affects prioritizing, promoting, and marking certain emotional registers as appropriate and desirablehope, happiness, being in charge, forward-looking aspiration, cosmopolitan solidarity, and selfassistance - while disqualifying others as nondesirable - temper, irritation, anger, fear, dread, stress, and sorrow (Kimura, 2018). Emotionalism consists in an institutionalization of affects, prioritizing and selecting emotions according to their supposedly positive and negative contribution to the achievement of the objectives of adaptation facilitators. Emotions supposed to contribute to consent to a contaminated life are placed at the top of the ranking, while negative emotions, namely that may contribute to the questioning of the legitimacy of adaptation to contamination, are rated at the bottom and approached as sicknesses to be cured. However, as stated by Kimura (2018, p. 113), "[a]nger and anxiety are not intrinsically worse than hope and happiness; among other things, they might inspire social movements to demand accountability for injustices." On his side, Horkheimer 
(1993, pp. 244-245) establishes that "[f]ear can lead to conformism, but if it is conscious and reflexive, it can also break down conformism and found the solidarity without which the individual is unthinkable."

The political economy of consent to nuclear increasingly involves the development of tools and methods aiming at quantifying the perception of nuclear risk and of the associated emotions and feelings. Ignoring the social character of emotions considered as pure biological responses, the "psychometric paradigm" is a key tool of the nuclear risk communicators literature searching for new methods aiming expressly at "[r]educing fears, stress and anxiety, and help to build mutual understanding and trust that will contribute to future success of the revitalizing efforts related to remediation and waste management" (Lyamzina, 2016).

In such background of emotionalism equipped with the commensurability of people's affects, by pretending to help free people from their fear, resilience and its apostles reduce to silence the freedom to fear. Governing through fear, as recommended by resilience advocates, means urging everyone to fear fear itself. On the contrary, drawing on Günther Ander's analysis, the freedom to fear refers to the ability of a given population to[f]eel fear to the extent of the danger looming over it, to feel the amount of anxiety that we must feel if we really want to free ourselves from the right to be freed from fear, and to feel fear in order to be free. (Anders, 2002, p. 296)It is thus hardly surprising to observe the erosion of this freedom, in the light of the stigma and pressure put on women, who in Fukushima are accused of "radiophobia" when they express their concerns to the medical staff with regard to the health of their children (Kimura, 2016). The medical expert Shunichi Yamashita, former director of the Health Management Survey, recently (re)stated that: "In Fukushima, fear is the killer" (New Scientist, 3125, May 13, 2017). The former "radiation risk management adviser" to the Fukushima prefecture, "special professor to the president" at FMU and Executive Advisor to the President of the RERF, is famous for the statement he made on March 20 2011, a pinnacle of emotionalism: "[t]he effects of radiation do not come to people who are happy and laughing, they come to people who are weak-spirited, that brood and fret." 7

The justification brought by Yamashita of its own declaration clearly belongs to the political economy of consent we are trying to excavate:Stress is not good at all for people who are subjected to radiation. Besides, mental-state stress also suppresses the immune system and therefore may promote some cancer and non-cancer diseases. That is why I told people that they also have to relax. (Spiegel, August 19, 2011) A point never highlighted by commentators is that such statements should not be regarded as a gaffe or a joke since it belongs to a long tradition of moralization of outbreaks which has extended its empire to all kinds of disasters. It is indeed here a matter of moralizing radioactive contamination and its consequences. Faithful to psychologization consisting in undermining the reality of a disaster, that is, the fact that such reality precisely has to be explained, Yamashita mobilizes a prophylactic characterology of the irradiated individual long since abandoned in other public health domains. Thus, in the plague-devastated England of the 16th and 17th centuries, the prevailing idea was that "the happy man does not get plague," while London health bureaucrats considered that the real preventive factors of the cholera epidemic of 1832 were "healthy bodies and joyful and serene minds," and an English surgeon asserted in 1845 that "grief and anxiety are the most common causes of breast cancer" (Sontag, 1993, pp. 75, 77, 186).

Moralization is a key feature of the political economy of consent. Transposing the radiation contaminated environment conducive to physical illness into a psychologically contaminated environment conducive to mental illness to which resilience is intended to remedy is indeed a powerful way to lay the blame on those enduring the contamination situation. Explaining to them that they are the cause of their troubles is also a way to root in them the idea that, after all, they deserve it. Ultimately, psychologization contributes to obstructing the development of a real 
knowledge of and consideration to actual psychological pathologies as an integral and seemingly unavoidable part of the public health response to nuclear accidents (Tsujiuchi et al., 2016).

According to Yamashita, "fear kills," because it makes one do foolish and risky things - flee, panic, live outside the environment one is accustomed to, change schools for the children, abort-with regard to a danger which is, in his eyes, just pure fantasy, that is, exposure to radioactivity. Translating Yamashita, we could say that it is fear, that is, the consciousness that remains in each one's powerlessness and desire for freedom, that kills, that is, prevents the forces of life to regain control.

It is a strange paradox that beyond the rejuvenating elixir of ignorance in which everyone is invited to dip, this ostracizing involves blaming those who fear the destructive effects of radioactivity on their lives, of destroying life by refusing to remain unconscious and by affirming their fear. Put differently, they refuse to entrust their fate to a superior biological order - that is, natural selection - assumed to be the only one capable of deciding, on behalf of everyone, what should be considered as forces of life and what should not.

Even before it was officially designated, "radiophobia" was a central and constant concern for the authorities in charge of nuclear power who recommended a treatment involving a "form of conditioning process" which must be based on familiarization with radioactivity and the development of an "emotional and intellectual understanding" toward it (WHO, 1958, p. 43).

It may be recalled that conditioning is a term used in biology and behavioral psychology. The expected results of conditioning and perfect adaptation are internalization and the acceptance of pressure and social constraints. Hardly surprising in principle, this conditioning nevertheless encourages people to submit to deadly mimicry, a term which, in biology, describes " $[\mathrm{t}] \mathrm{he}$ mimetic process by which an organic being equates itself to an inorganic being in order to blend with it in terms of appearance, in other words, an adaptation process which results in the imitation of what is dead" (Adorno, 2011, p. 79).

One can hardly expect more from the advocates of a resilience which, ultimately, in terms of methodology, seeks to expropriate the unconscious through social control instead of ensuring that individuals become aware of their unconsciousness. To this end, two conceptual and empirical allies are mobilized: contingency and equivalence.e.

\section{Contingency and Equivalence}

Governing through the fear of fear to which the advocates of resilience subscribe calls on each one to overcome accidents rather than rely on increasing awareness of her or his helplessness, which may awaken fear and thus raise awareness of one's freedom. Moreover, in this repression process, contingency is both at the origin of and expected to resolve the situation and is seen as a principle of progress.

Thus, the former Director general of the Institut de Radioprotection et de Sûreté Nucléaire (IRSN), Jacques Répussard, considers that "it is inevitable that some regions have low levels of contamination" and proposes to "restore the individual and collective freedom." To this end, he suggests that "[n]o 'lines' should be drawn according to the levels of radiation and defining areas suitable to the maintenance or return of the people" because "the threshold dose has become a political value lacking any public health significance and preventing the return of some people who would like to return" (Actu-Environnement, March 10, 2016). 
It is also a question of contingency when Vadym Chumak, of the Academy of Science of Ukraine, asserts that[r]adioactivity is like the lottery. You can buy a ticket and win the jackpot, or buy seven tickets and win nothing at all. The more you buy tickets, the more your chances of winning. At Fukushima, very few tickets were distributed, so there will be very few winners. (Interview, FMU, September 11, 2011) From previously quoted Yamashita to Chumak, we notice the strength, the efficacy as well as the plasticity of a nuclear disaster theodicy according to which the effects of radiation exposure can both be considered as a castigation threatening all those deviant "others" who misbehave by not smiling and displaying a bad temper, and as a blind contingency driven unfortunate evil able to strike anyone indiscriminately.

This paradoxical conquest of freedom through submission to contingency (and the related produced ignorance) is based on a second ally of convenience: equivalence. Indeed, the "living with" contamination (and decontamination) motto implies a rise in disaster management where risks are administered through a growing technological control and a strengthening of security requirements and devices. Fear itself (including the underlying freedom) which has now become a risk becomes an object of control and planning, since it has to be domesticated.Thus, there is also a rise in commensurability, that is, equivalence gains ground.

Specifically, when fear becomes itself a commensurable object, an additional step is taken in equivalent thought which[p]roduces by itself a rationality related in principle to that of the administration, insofar as it ensures that all objects are commensurable, that they are subsumable under abstract rules. Qualitative differences between and across fields are ironed out and their resistance against the administration is thus reduced. (Adorno, 2011, p. 231)The main stake of viewing radioactivity - and the associated risks - as a commensurable object lies in the commensurability of anxiety itself, which is involved in its institutionalization. By relating fear to equivalent thought, it is a question of transforming it into an object of exchange and optimization and assigning it an exchange value. "Balancing" fear with other "externalities"-couple's separations, discriminations, suicides, and unemployment - and elaborating an abstract equivalence between concrete incomparable objects, is part of this process resilience is built upon.

The idea of "the balancing of lifestyle considerations to make sound decisions with regard to daily exposures and to take control over one's own life," and that we can and must adopt a "reasonable" attitude in the midst of disaster, as it has become true that, in substance, "life is not just about health" (IRSN, 2016), is part of this empire of equivalent thought.

Giving free reign to governance through contingency and equivalence guards against a return to freedom perceived as threatening and a source of social disorder detrimental to the "freedom to return." Contingency and equivalence are functionally related to resilience, which emerges here as the art of raising one's head and consent to a world of quantity fully subject to unmastered probabilities.

\section{Conclusion}

Based on the case of the Fukushima Daiichi nuclear disaster, we have showed how, facing the aporia of irreversible biological effects induced by radiation exposure, resilience operates as a technology of consent, offering substitute issues such as empowering individual and rebuilding communities. We have also illustrated that resilience paves the way to new "forms of life" characterized by a dispossession of power through the consent to ignorance and the relativization of existing knowledge and by a submission to protection through the self-management of disaster and its aftermath. Governing through coding the risk as fear itself, resilience is a key tool in the manufacturing of consent, consisting in learning to fear fear itself in order not to fear one's own 
deterioration. This is achieved through the institutionalization of affects consisting in selecting emotions according to their supposedly positive and negative contribution to adaptation. Indeed, the making of consent involves the making of passion from individuals for the situation in which they are placed and consequently involves the making of their fear of fearing this situation. To consent is to live obedience but relieved from its intrinsic burden by a joyful affect. Thus, freedom to fear is reduced to silence.

In sum, the political economy of consent to the nuclear, of which resilience is one of the technologies, can be grasped at four interrelated analytical levels paving the way for further investigation. The first level is technological. It refers to consent through and to the nuclear technology but also through and to the technologies of survival and their subsequent industries which are supposed to respond to the nuisances of the nuclear technology. The call for resilience launched from all sides by the administrators of the Fukushima nuclear disaster comes within the scope of the long series of blow-by-blow technical ripostes responding to the failures of previous solutions by adding new failures.

The second level is sociometabolic. Consent to nuisance makes the "living with" motto becoming inescapable. Resilience aiming at humanizing by any means the constraints imposed by adaptation, nuclear risk communicators are constantly calling for selected positive emotions. The objective is to remove from fear-an irrational attitude-its actual external object, and transformed into a subjective story, the accident becomes no more than an issue individuals must deal with and overcome by themselves, a personal fear to conquer which, as soon as it is eliminated, wipes out risk itself. Consent through resilience aims at curing the complexes of individuals and releasing them from so called irrational burdens without changing the whole these burdens belong to, thus leading to repression and hardening among them.

The third level is political. Consent to participation establishes through comanagement of the aftermath the deresponsibilization of those responsible. By transforming its victims into actorsexperts, the disaster becomes a field in which their capability of resistance is experimented upon. In so doing, the very status of victim is diluted into the comanagement of damage and that of disaster into the advent of a new beginning promised by resilience. The individual comanagement of disaster occurs alongside its absorption across society as a whole.

The fourth level is epistemological. By consenting to ignorance, the public learns how to ignoreand how not to act based on - what it already knows concerning the health effects of radiation exposure. By sinking existing knowledge into the ocean of indefinite controversies and uncertainties, consent to ignorance contributes to an epistemic procrastination. Each one is called to be a satisfied irradiated person, the objective being to "free minds" where, in reality, it is the bodies that risk degradation. Resilience is actually in conflict with the organic being: It seeks to couple the living body with the inorganic world of ionizing radiations and with the realm of the technical devices in charge of monitoring the decay of the living. Regarding the living, resilience champions the rights of the corpse.

Transversal to the previous ones, a fifth cognitivo-experimental level can be identified. Beyond encouraging social acceptance and individual responsibility, one important feature of the political economy of consent unveiled in the Fukushima nuclear disaster context is the consent to experimentation, learning, and training. Disaster mitigation appears as a way to experiment the modalities for risk communication strategies allowing close observation of the population's behavior and reaction to quantification tools and processes, to fear, to public authorities and experts. Concepts such as empowerment and practical radiological culture as well as their associated technologies of consent such as resilience are put to the test of reality and implementation, consequently allowing adjustments and refinements of disaster management protocols, including at 
international level. A third aspect is to allow the authorities to experiment the possibilities and the conditions of the "return" policies, identifying the best methods, the limits and the tolerance thresholds in terms of evacuation duration, of living apart period for separated families and of adaptation to new material and social contexts.

Individual real-life experiences provide the material for a life-size experiment of social, political, scientific, and medical nature, where the capacities of individuals to adapt to extreme situations are challenged and tested. Besides aiming at legitimizing the decontamination business and the reconstruction investments, thus stimulating the economic wheel, mitigation policies are also a way to learn and to demonstrate that in time of nuclear disaster, evacuation is not anymore necessary since it is costly and disastrous in terms of psychosocial trauma. Ultimately, as a technology of consent, resilience contributes to the justification of what is being "resiliated," that is, the nuclear disaster and its aftermath.

By establishing resilience as a prenuclear disaster management tool (probably for the next one), scientists, experts and political leaders turn the disaster not into an event that happens but into a symptom of unpreparedness for whatever is happening. They shift substantially the original cause of the damage perpetrated. The concept of resilience provides a pseudotheoretical framework that lends itself perfectly to consenting to the worst. Built with citizens in a democratic manner, this consent places each one in a position where she or he merely actively prepares for the next disaster, which, like the previous ones, is likely to be just as singular and thus uncontrollable, even though its probability will be "measurable." Essentially, since being self-sufficient, felicity does not question much, the challenge is to learn to "live with" disaster with zest, by counting on miraculously falling on the right side of the stochastic distribution. Resilience is to nuclear disaster management, what astrology is to every one's life: a call for resignation, camouflaged as realism and hope, that helps silence awareness and obscures it.

\section{Acknowledgments}

The analysis proposed here owes much to the collaboration and multiple exchanges since March 2011 with Cécile Asanuma-Brice, research associate at Clersé-CNRS-University of Lille 1 and French Research Institute on Japan (MEAE-CNRS) in Tôkyô, Anne Gonon, Professor at Doshisha University in Kyoto, Shinobu Goto, Professor at the Graduate school of Symbiotic Systems Sciences at the University of Fukushima, Kyō Kageura, Professor in the Department of information sciences at the University of Tokyo, all to whom I extend my gratitude. A very special thanks goes to Majia Holmer-Nadesan, professor in the School of Social and Behavioral Sciences at the Arizona State University in Phœnix, for her encouragements and comments on an early draft version and to Nadine Ribault, novelist and essayist, who far much better than I do, knows how much resilience can be a repressive and regressive notion in disaster situations. The final version of this article was considerably improved thanks to the crucial comments and suggestions made by the reviewer(s), and to the patience and cooperation of the editors.

\section{Declaration of Conflicting Interests}

The author(s) declared no potential conflicts of interest with respect to the research, authorship, and/ or publication of this article.

\section{Funding}


The author(s) disclosed receipt of the following financial support for the research, authorship, and/ or publication of this article: For the first elaboration and draft of this paper, I received the support of the EURIAS (European Institutes for Advanced Study) Fellowship Programme during my fellowship at HWK Institute for Advanced Study Delmenhorst, Germany, in 2016-2017. CLERSECNRS laboratory and University of Lille supported the translation costs.

\section{Notes}

1. Fukushima Future Center for Regional Revitalization is an ad hoc academic and political initiative created in April 2013 supporting the Japanese policy of "resilience." This calls for scientific activities (especially metrology) as well as for the training and education of children.

2. Only the defenders of the hormesis theory holds such radical position which, as we will see, lacks support from scientific evidence.

3. Radiation Effects Research Foundation (RERF) was established in 1975 as a nonprofit foundation by Japan and the United States. RERF was preceded by the Atomic Bomb Casualty Commission (ABCC), established in 1947 by the U.S. National Academy of Sciences with funding from the U.S. Atomic Energy Commission.

4. Møller, Mousseau, Nishiumi, Suzuki, and Ueda (2013) found elevated mutations rates and levels of genetic damage, increased frequencies of developmental abnormalities including tumors and cataracts, shortened life spans, and decreased fertility, including at low dose, for the flora and fauna inhabiting contaminated regions of Ukraine and Belarus. Their results in Fukushima strongly suggest that many bird species and some groups of insects have been significantly impacted. Studies on health effects on humans show that the three most important aspects of exposure to radioactive fallout are cancer-fatalities estimated between 30,000 and 60,000 deaths in the lifetime of those alive at the time of the Chernobyl accident-somatic noncancer diseases, and hereditary diseases (Baverstock \& Williams, 2006).

5. For an account of the structural links between ABCC-RERF and the far right-wing Sasakawa Memorial Health Foundation, one of the "tentacles" of the Nippon Foundation, see Ribault and Ribault (2012).

6. The term "radiation phobia syndrome" was introduced in 1987 by the Russian physicists Ilyin and Pavlovskij (1987, p. 24) to qualify the mental state of the victims of the Chernobyl disaster: "The tension and chronic state of stress are causing radiation phobia syndrome in part of the population and may, in the current radiation situation, pose an even greater threat to health than exposure to radiation itself."

7. Broadcasted on German TV-channel ZDF, October 4, 2011 (German, English subs), min. 5.57. Accessed May 3, 2019, https://www.youtube.com/watch?v=V1T4Ac9nHeY; see also Spiegel, August 19, 2011.

\section{References}

AdgerW. N. (2000). Social and ecological resilience: Are they related? Progress in Human Geography, 24, 347-364. 
AdornoT. W. (2003). Prismes, critique de la culture et société. [Prims: Cultural Criticism and Society]_Paris, France: Payot.

AdornoT. W. (2011). Société: Intégration, désintégration. [Society: Integration and Disintegration] Paris, France: Payot.

AmmonO. (1896). Die Gesellschafts-Ordnung und ihre natürlichen Grundlagen [Social order and its natural application]. Jena, Germany: G. Fischer.

AndersG. (2002). L'obsolescence de l'homme. Sur l'âme à l'époque de la deuxième révolution industrielle. [The Outdatedness of Human Beings. On the Soul in the Era of the Second Industrial Revolution]_Paris, France: Editions de l'Encyclopédie des Nuisances/Ivrea.

AndoR. (2016). Reclaiming our lives in the wake of a nuclear plant accident. Clinical Oncology, 28, $275-276$.

Asanuma-BriceC. (2015). De la vulnérabilité à la résilience, réflexions sur la protection en cas de désastre extrême. Raison Publique. Retrieved May 3, 2019, from http://www.raison-publique.fr/ $\underline{\operatorname{article} 771 . \mathrm{html}}$

BaverstockK. (2013). Reflections on the Chernobyl accident and WHO's Response. Unpublished draft report.

BaverstockK.WilliamsE. D. (2006). The Chernobyl accident 20 years on: An assessment of the health consequences and the international response. Environmental Health Perspectives, 114, 13121317.

BielloD. (2011). Japan's nuclear crisis renews debate over environment, health and global energy use. Health Affairs, 30, 811-813.

BoudiaS. (2013). From threshold to risk: Exposure to low doses of radiation and its effects on toxicants regulation. In BoudiaS.JasN. (Eds.), Toxicants, health and regulation since 1945 (pp. 7187). London, England: Pickering \& Chatto.

Cichetti, D. (2010). Resilience under conditions of extreme stress: a multilevel perspective. World Psychiatry, oct. 9(3): 145-154.

ChandlerD.ReidJ. (2016). The neoliberal subject: Resilience, adaptation and vulnerability. London, England: Rowman \& Littlefield International.EvansB.

ReidJ. (2014). Resilient life. The art of living dangerously. Oxford, England: Polity Press.FederA.NestlerE. J.

CharneyD. S. (2009). Psychobiology and molecular genetics of resilience. Nature Reviews Neuroscience, 10, 446-457.

FolkeC. (2006). Resilience: The emergence of a perspective for social-ecological systems analyses. Global Environmental Change, 16, 253-267.

FrantzeskakiN.LoorbachD.MeadowcroftJ. (2012). Governing transitions to sustainability. International Journal of Sustainable Development, 15, 19-36.

FujinoM. (2013). Social impact of Fukushima Daiichi Nuclear power plant accident. Lecture at FMU-IAEA International Academic Conference, Radiation, Health, and Society. Fukushima, November 21-24. 
FunabashiY.KitazawaK. (2012). Fukushima in review: A complex disaster, a disastrous response. Bulletin of the Atomic Scientists, 68, 9-21.

FurutaK. (2013, May 20). What is resilience engineering? Conference at the Resilience Engineering Research Center, University of Tokyo, Tokyo, Japan.

GabelJ. (1962). La fausse conscience. [The false consciousness] Paris, France: Les Editions de Minuit.

GabelJ. (1970). Sociologie de l'aliénation. [Sociology of alienation]_Paris, France: Presses Universitaires de France.

GononA. (2017, October 14). La triple catastrophe du Japon de l'Est-Un espace liminaire et des sujets citoyens. [The triple disaster of Eastern Japan - An initial space and subjects citizens] Lecture at Symposium Lost in Ignorance: Fukushima, Maison franco-japonaise, Tōkyō, Japan.

HallP. A.LamontM. (2013). Social resilience in the Neoliberal Era. Cambridge, MA: Cambridge University Press.

Hériard DubreuilG. (2011, November 17-18). Après Fukushima: l'éventualité d'une contamination radioactive durable. [After Fukushima: the possibility of a long term radioactive contamination] Lecture at NERIS Workshop, Orsan, France.

Hériard DubreuilG.LavelleS.GadboisS.MaysC.SchneiderT. (2010). Démocratie constructive et gouvernance de la technique. [Constructive democracy and governance of technics]. Revue Gouvernance, Hiver, 7, 1-15.

HermanE. S.ChomskyN. (1988). Manufacturing consent. The political economy of the mass media. New York, NY: Pantheon Books.

HindmarshR. (2013). Nuclear disaster at Fukushima Daiichi: Introducing the terrain. In HindmarshR. (Ed.), Nuclear disaster at Fukushima Daiichi: Social, political and environmental issues (pp. 1-21). New York, NY: Routledge.

HiranoK.KasaiH. (2016). Interview with Koide Hiroaki-The Fukushima Nuclear Disaster is a serious crime. The Asia-Pacific Journal, 14, 1, Retrieved May 3, 2019, from https://apjjf.org/Katsuya-Hirano--Hirotaka-Kasai/4865/article.pdf

HorkheimerM. (1993). Notes critiques (1949-1969)-Sur le temps présent. [Critical notes 1949-1969 - On present time] Paris, France: Payot.

IllouzE. (2007). Cold Intimacies: The making of emotional capitalism. Oxford, England: Polity Press.

IllouzE.CabanasE. (2017). The making of a "happy worker": Positive Psychology in neoliberal organizations. In PughA. (Ed.), Beyond the cubicle: Insecurity culture and the flexible self (pp. 2550). New York, NY: Oxford University Press.

IlyinL. A.PavlovskijO. A. (1987). Radiological consequences of the Chernobyl accident in the Soviet Union and measures taken to mitigate their impact. IAEA Bulletin, 4, 17-24.

International Physicians for the Prevention of Nuclear War/Physicians for Social Responsibility. (2016). 5 Years living with Fukushima - Health effects of the nuclear catastrophe. Retrieved May 3, 2019 from https://www.psr.org/wp-content/uploads/2018/06/chernobyl-fukushima.pdf 
IRSN (Institut de Radioprotection et de Sûreté Nuclaire). (2016). Kotoba, dialogues in Fukushima. Retrieved from http://www.fukushima-dialogues.com/

KatzC. L. (2013, November 21-24). Disasters, mental health, and radiation. Lecture at FMU-IAEA International Academic Conference, Radiation, Health, and Society, Fukushima.

KeraD.RodJ.PeterovaR. (2013). Post-apocalyptic citizenship and humanitarian hardware. In HindmarshR. (Ed.), Nuclear disaster at Fukushima Daiichi: Social, political and environmental issues (pp.97-115). New York, NY: Routledge.

KimuraA. H. (2016). Radiation brain moms and citizen scientists: The gender politics of food contamination after Fukushima. Durham, NC: Duke University Press.

KimuraA. H. (2018). Fukushima ETHOS: Post-disaster risk communication, affect, and shifting risks. Science as Culture, 27, 98-117.

KitamuraM. (2011, June 14). Lessons from the Fukushima accident and the issue of "nuclearsociety." Conference at the Atomic Energy Committee, Japanese Prime minister Cabinet Office, Tōkyō, Japan.

KoideH. (2014, November 22-24). Past, present and future of the Fukushima Daiichi NPP Accident. Pre-event Special Lecture The 4th Citizen-Scientist International Symposium on Radiation Protection, Tokyo, Japan.

LeuraudK.RichardsonD. B.CardisE.DanielsR. D.GilliesM.O’HaganJ. A.,...KesminieneA. (2015). Ionising radiation and risk of death from leukaemia and lymphoma in radiation-monitored workers (INWORKS): An international cohort study. The Lancet Haematology, 2, e276-281. Retrieved May 3, 2019. doi:10.1016/S2352-3026(15)00094-0

LindeeS. (2016). Survivors and scientists: Hiroshima, Fukushima and the radiation effects research foundation, 1975-2014. Social Studies of Science, 46, 184-209.

LochardJ. (2011). Blog of ethos in Fukushima. December 6. Retrieved May 3, 2019, from http:// ethos-fukushima.blogspot.com/2011/12/jacques-lochard_2495.html

LochardJ. (2013, November 21-24). The human dimensions of nuclear post-accident situations. Lecture at FMU-IAEA International Academic Conference, Radiation, Health, and Society, Fukushima.

LutharS. (2006). Resilience in development: A synthesis of research across five decades. In CicchettiD.CohenD. (Eds.). Developmental psychopathology (Vol. 3., pp. 739-795). New York, NY: Wiley.

LyamzinaY. (2016, June 1-3). Assistance to the IAEA member states for developing effective risk communications throughout integrating perceived risk and actual risk in public communications. Lecture at RICOMET 2016, Bucharest, Romania.

MarquisN. (2018, March 13). La résilience comme attitude face au malheur: succès et usages des ouvrages de Boris Cyrulnik. SociologieS On line. Retrieved May 3, 2019, from http:// journals.openedition.org/sociologies/6633

MEXT (Ministry of Education, Culture, Sports, Science and Technology). (2012). White Paper on Science and Technology 2011, toward a robust and resilient society-Lessons from the Great East 
Japan Earthquake-, Ministry of education, research and technology. Strategic Programs Division, Science and Technology Policy Bureau, Tōkyō.

MøllerA.MousseauT.NishiumiI.SuzukiH.UedaK. (2013). Differences in effects of radiation on abundance of animals in Fukushima and Chernobyl. Ecological Indicators, 14, 75-81.

MoritaA.BlokA.KimuraS. (2013). Environmental infrastructures of emergency: The formation of a civic radiation monitoring map during the Fukushima Disaster. In HindmarshR. (Ed.), Nuclear disaster at Fukushima Daiichi: Social, political and environmental issues (pp. 78-96). New York, NY: Routledge.

NadesanM. (2013). Fukushima and the privatization of risk. New York, NY: Palgrave Pivot.

NadesanM. (2019). Nuclear governmentality: Governing nuclear security and radiation risk in PostFukushima Japan. Unpublished paper.

NestoroskaM. S. (2017, June 27-29). Building community resilience: Emergency preparedness and involvement of interested parties. Lecture at RICOMET 2017, Vienna, Austria.

NiwaO.LochardJ.ClementC. (2016, September 27). From Chernobyl to Fukushima: What ICRP has learned with Japanese stakeholders? Lecture at 5th International Expert Symposium in Fukushima on Radiation and Health, Fukushima Medical University, Japan.

OzasaK.ShimizuY.SuyamaA.KasagiF.SodaM.GrantE. J.,..KodamaK. (2012). Studies of the mortality of atomic bomb survivors, Report 14, 1950-2003: An overview of cancer and noncancer diseases. Radiation Research, 177, 229-243.

PisanoU. (2012). Resilience and sustainable development: Theory of resilience, systems thinking and adaptive Governance (ESDN Quarterly Report No. 26). Vienna, Austria: European Sustainable Development Network (ESDN).

PolleriM. (2019). Conflictual collaboration: Citizen science and the governance of radioactive contamination after the Fukushima nuclear disaster. American Ethnologist, 46, 214-226.

ProctorR.,SchiebingerL. (Eds.). (2008). Agnotology: The making and unmaking of ignorance. Palo Alto, CA: Stanford University Press.

RibaultN.RibaultT. (2012). Les sanctuaires de l'abîme-Chronique du désastre de Fukushima. Paris, [The sanctuaries of abyss - Chronicle of the Fukushima disaster] France: Éditions de l'Encyclopédie des Nuisances.

SatoY.TaguchiT. (2016). Datsugenpatsu no tetsugaku [in Japanese] [Philosophy of the exit of nuclear], Kyoto, Japan: Jimbun-shoin.

SebaldW. G. (2004). De la destruction comme élément de l'histoire naturelle. [On the natural history of destruction] Arles, France: Éditions Actes Sud.

SemprunJ.RieselR. (2008). Catastrophisme, administration du désastre et soumission durable. [Catastrophism, disaster administration and sustainable submission] Paris, France: Éditions de l'Encyclopédie des Nuisances.

SHAMISEN Project Report. (2017). Recommendations and procedures for preparedness and health surveillance of populations affected by a radiation accident. Retrieved May 3, 2019, from www.radiation.isglobal.org 
SontagS. (1993). La maladie comme métaphore-Le sida et ses métaphores. [Illness as metaphor and AIDS and its metaphors] Paris, France: Christian Bourgeois Editeurs.

TonakiY. (2016). La banalité résiliente des catastrophes: d'Après Fukushima de Jean-Luc Nancy. [The resilient banality of disasters: from After Fukushima of Jean-Luc Nancy] Rue Descartes 2016/1, 88, 66-83.

TopçuS. (2013). Chernobyl empowerment? Exporting participatory governance to contaminated territories. In BoudiaS.JasN. (Eds.), Toxicants, health and regulation since 1945 (pp. 135-158). London, England: Pickering \& Chatto.

TsudaT.TokinobuA.YamamotoE.SuzukiE. (2015). Thyroid cancer detection by Ultrasound among residents ages 18 years and younger in Fukushima, Japan. Epidemiology (Cambridge, Mass.) 27.TsujiuchiT.YamaguchiM.MasudaK.TsuchidaM.InomataT.KumanoH.,...MollicaR. F. (2016). High Prevalence of post-traumatic stress symptoms in relation to social factors in affected population one year after the Fukushima nuclear disaster. Retrieved May 3, 2019, from https:// journals.plos.org/plosone/article?id=10.1371/journal.pone.0151807

VoßJ. P.BornemannB. (2011). The politics of reflexive governance: Challenges for designing adaptive management and transition management. Ecology and Society, 16, art. 9.WelshM. (2014). Resilience and responsibility: Governing uncertainty in a complex world. The Geographical Journal, 180, 15-26.

World Health Organization. (1958). Mental health aspects of the peaceful uses of atomic energy: report of a study group (Technical Report No. 151). Geneva, Switzerland. 